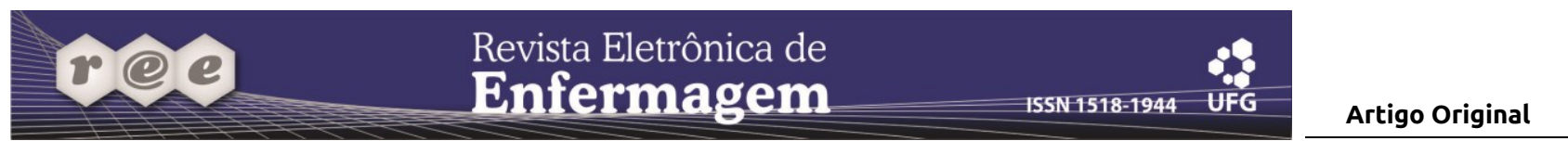

\title{
Atuação do enfermeiro a usuários de álcool e de outras drogas na Saúde da Família
}

The care of alcohol and other drug users by Family Health nurses

Actuación del enfermero hacia usuarios de alcohol y otras drogas en la Salud de la Familia

Luccas Melo de Souza ${ }^{1}$, Maria Getúlia Pinto²

\section{RESUMO}

Este trabalho trata-se de estudo exploratório-descritivo, com abordagem qualitativa, que objetivou identificar como enfermeiros atuantes na Saúde da Família abordam a temática do álcool e de outras drogas. Foram abordados oito enfermeiros por meio de entrevistas semiestruturadas. A maioria dos entrevistados considera que esse tema está inserido no cotidiano das equipes, pois é um problema de saúde pública, com agravantes sociais. A detecção dos usuários na comunidade é realizada, na maioria das vezes, pelos Agentes Comunitários de Saúde ou pelos familiares dos usuários. A vontade de reabilitação do usuário e o vínculo dele com os profissionais de saúde são indispensáveis para o tratamento. Entre os desafios encontrados está a falta de conhecimento para detectar e assistir os usuários, além da dificuldade de vínculo com eles. Ressalta-se a necessidade de maior capacitação dos enfermeiros da atenção primária para atuarem no tratamento de usuários de álcool e de outras drogas.

Descritores: Enfermagem; Drogas llícitas; Programa Saúde da Família; Alcoolismo.

\section{ABSTRACT}

This exploratory-descriptive study was performed using a qualitative approach, with the objective to identify how Family Health nurses address the issue of alcohol and other drugs. Semi-structured interviews were performed with eight nurses. Most participants consider that this topic is included in the everyday work of the teams, because it is a public health problem with social effects. The detection of users in the community is usually made by Community Health Agents or by the users' relatives. They consider that the users' desire to undergo rehabilitation and their attachment to healthcare professionals are indispensible for effective treatment. The identified challenges include the lack of knowledge in regards to detecting and caring for users, in addition to the difficulty in establishing a relationship with them. It is emphasized that there is a need to prepare primary healthcare nurses to work with users of alcohol and other drugs.

Descriptors: Nursing; Street Drugs; Family Health Program; Alcoolismo.

\section{RESUMEN}

Estudio exploratorio-descriptivo, con abordaje cualitativo, que objetivó identificar cómo los enfermeros que actúan en la Salud de la Familia abordan la temática del alcohol y otras drogas. Fueron entrevistados ocho enfermeros mediante entrevistas semiestructuradas. La mayoría de los entrevistados considera que ese tema está inserto en el cotidiano de los equipos, dado que es un problema de salud pública con agravantes sociales. La detección de usuarios en la comunidad es efectuada mayoritariamente por Agentes Comunitarios de Salud o por familiares de usuarios. Consideran que la voluntad de rehabilitación del usuario y su vínculo con los profesionales de salud son indispensables para el tratamiento. Entre los desafíos encontrados se cuentan: la falta de conocimiento para detectar y atender al usuario, además de la dificultad del vínculo con ellos. Se resalta la necesidad de mayor capacitación del enfermero de atención básica para actuar en tratamiento de usuarios de alcohol y otras drogas.

Descriptores: Enfermería; Drogas Ilícitas; Programa de Salud Familiar; Alcoholismo.

\footnotetext{
${ }_{1}^{1}$ Enfermeiro, Doutor em Enfermagem. Professor Adjunto, Universidade Luterana do Brasil. Gravatai, RS, Brasil. E-mail: luccasms@gmail.com.

2Enfermeira. Gravatai, RS, Brasil. E-mail: mgbarcelos@yahoo.com.br.
} 


\section{INTRODUÇÃO}

O consumo excessivo de álcool e de outras drogas tornou-se importante fator de risco para determinadas morbimortalidades, refletindo em incapacidade para atividades e em menor tempo de vida para os seus usuários. O uso abusivo dessas substâncias acarreta implicações legais e danos de ordem física, mental e social, tais como a exposição à violências, acidentes, relações sexuais sem a devida proteção, propagação de doenças infecciosas, isolamento social e ruptura familiar ${ }^{(1-2)}$.

No Brasil, a partir da década de 80, o Governo Federal começou a desenvolver pequenas iniciativas em relação às drogas. A Política de Atenção Integral aos Usuários de Álcool e de outras Drogas foi efetivada somente em 2003. Com essa política, o governo responsabiliza-se de forma integral e articulada pelo desafio de prevenir, tratar e reabilitar os usuários, considerando a questão como um problema de saúde pública, não mais com uma visão restrita de um problema jurídico-policial(3-4).

Com essa premissa, o Ministério da Saúde (MS) salienta a necessidade de estruturação e de fortalecimento de uma rede de assistência centrada na atenção comunitária associada à rede de serviços de saúde e social, enfocando a reabilitação e a reinserção social dos usuários de álcool e de outras drogas. Considera que a oferta de cuidados a pessoas com problemas decorrentes do uso dessas substâncias deve ser embasada em dispositivos extra-hospitalares de atenção psicossocial especializada, devidamente articulados à rede assistencial em saúde mental e ao restante da rede de saúde ${ }^{(4)}$. Nessa perspectiva, surge a importância da estruturação da Atenção Primária por meio da Saúde da Família (SF), fundamentada no discurso que busca romper com o modelo biomédico e fragmentado em especialidades, considerando-a como o primeiro acesso dos usuários ao Sistema Único de Saúde (SUS).

$\mathrm{Na} \mathrm{SF}$, o enfermeiro tem grande potencial para reconhecer os problemas relacionados ao uso de álcool e de outras drogas, bem como em desenvolver ações assistenciais, tendo em vista que mantém contato próximo aos usuários dos serviços de saúde(5), sendo necessária contínua análise da sua praxe profissional. No Brasil, a investigação dos problemas relacionados ao uso de drogas vem sendo investigada com maior magnitude na última década, havendo ainda, uma lacuna sobre essa temática(2), ênfase para a realização de novos estudos, em distintas realidades, haja vista as diferenças culturais encontradas no país.

Recentemente, estudo(2) realizado com enfermeiros na Amazônia revelou falta de formação universitária, de educação permanente e de suporte referência-contrareferência na Atenção Básica em Saúde (ABS) à dimensão específica do álcool. Além disso, desconheciam os dados epidemiológicos relacionados ao álcool, bem como não visualizavam a ABS como mecanismo de apoio aos casos. Em João Pessoa (PB), estudo constatou carência na formação profissional de enfermeiros sobre o uso de $\operatorname{drogas}^{(5)}$.

No Rio Grande do Sul (RS), há necessidade de estudos envolvendo a abordagem do álcool e de outras drogas no contexto da SF, pois os estudos abordando a temática direcionam-se, principalmente, para o uso de álcool e de outras drogas em adolescentes e escolares/universitários. Ademais, em virtude da amplitude territorial do Brasil, com sua diversidade cultural, social e de saúde, é necessário identificar as realidades acerca dos problemas de saúde regionais, para se trabalhar as especificidades em seus contextos locais.

Diante da questão do uso de álcool e de outras drogas como problema de saúde pública, bem como o papel do enfermeiro na assistência aos usuários dessas substâncias, questiona-se: como os enfermeiros que atuam em atenção primária vinculados à SF percebem e abordam a temática do álcool e de outras drogas? Como é realizada a detecção e o atendimento aos usuários? Quais os desafios que o enfermeiro que atua na SF encontra para abordar os usuários?

Рага responder às questões, foi delineado o seguinte objetivo geral: identificar o modo como os enfermeiros, que atuam na SF de uma cidade da região metropolitana de Porto Alegre, abordam a temática do álcool e de outras drogas, no que se refere à detecção, condução e assistência aos usuários.

Identificar como os enfermeiros da SF abordam a problemática do álcool e de outras drogas permitirá contribuir para o fortalecimento, a elaboração, a implantação e a implementação de ações de enfrentamento desse problema, quer a nível individual, coletivo ou político. Além disso, possibilitará maior conhecimento da realidade regional, a fim de se 
(re)pensar políticas públicas de saúde e educacionais que preencham as possíveis lacunas no atendimento e na formação dos profissionais de saúde.

\section{MÉTODOS}

Trata-se de um estudo exploratório-descritivo, com abordagem qualitativa, realizado na Secretaria Municipal de Saúde (SMS) de uma cidade da região metropolitana de Porto Alegre-RS, especificamente em 10 Unidades de Saúde da Família (USFs) adscritas a essa SMS. Esta cidade possui 19 equipes de Saúde da Família (SF) habilitadas e distribuídas entre essas 10 USFs.

Foram entrevistados oito enfermeiros, após sorteio aleatório, que atuam em cinco das 10 USFs anteriormente citadas. O critério de inclusão para os enfermeiros foi: ter passado pelo estágio probatório, no intuito de entrevistar aqueles com maior tempo de experiência no serviço e com conhecimento da realidade local. Como critério de exclusão, utilizou-se: estar em situação de afastamento do trabalho (licença-saúde, licença-maternidade, acidente de trabalho, etc.) durante a realização do estudo.

A definição do número de sujeitos se deu pelo critério de saturação das informações, motivo pelo qual, ao final de oito entrevistas, observou-se a exaustão dos dados, momento em que foi encerrada a coleta de dados.

Para a coleta de informações, foi utilizada a técnica da entrevista semiestruturada, com as seguintes questões abertas: como você percebe a problemática do uso de álcool e de outras drogas na SF? Como realiza a detecção desses usuários? Qual o tipo de intervenção que você realiza? Existe algum programa/ação específico implantado nessa USF para atender a esses usuários? Quais os desafios para atender a esses usuários? Os dados foram coletados após informações sobre o objetivo da pesquisa e solicitação da assinatura do Termo de Consentimento Livre e Esclarecido.

As entrevistas ocorreram entre os meses de abril e junho do ano de 2010, individualmente, sendo gravadas em mídia eletrônica e transcritas posteriormente. Foram agendadas com antecedência e realizadas em um lugar onde se garantiu a privacidade do enfermeiro, em seu local e no seu turno de trabalho.

Após as entrevistas serem transcritas, os dados foram analisados pela técnica de Análise de Conteúdo, modalidade temática, proposta por $\operatorname{Bardin}^{(6)}$.
Primeiramente foi realizada uma leitura flutuante, a fim de aproximar/situar os pesquisadores com o material das entrevistas. Prosseguiu-se com a exploração do material coletado, momento em que foram selecionadas as unidades de registro, que deram origem aos temas. 0 processo originou três categorias temáticas. Seguiu-se com o tratamento e interpretação dos resultados e com a discussão com a literatura.

Os princípios éticos foram respeitados, seguindo a normas de pesquisa em saúde referidas pela Resolução n 196 do Conselho Nacional de Saúde. O projeto foi encaminhado e aprovado pelo Comitê de Ética em Pesquisa da Universidade Luterana do Brasil (protocolo 2010-082H).

Para manter a privacidade e o anonimato dos sujeitos, decidiu-se por não identificar o local de procedência dos participantes, bem como optou-se por dar-lhes codinomes iniciados por "ENF", relacionado à palavra enfermeiro(a), seguido por uma sequência alfabética aleatória, sem caracterizar a sequência das entrevistas.

\section{RESULTADOS E DISCUSSÃO}

Рага apresentação dos resultados apresentam-se as categorias, os dados pertinentes a cada uma delas e a discussão.

\section{Estendendo a visão: o álcool e de outras drogas como um problema social e familiar}

Pelo relato dos enfermeiros, observa-se que o tema sobre o uso de álcool e de outras drogas está inserido no cotidiano das equipes de saúde, pois é um problema que tem recebido ênfase, devido aos agravantes que acarretam ao usuário, à família e à população. Essa questão alcançou grandes proporções, sendo reforçada e caracterizada como um problema de saúde pública pelos profissionais entrevistados.

É um problema comum, problema de saúde pública bem grave, que está direcionado não só com o paciente, mas com a família. [...] Ele [o álcool] é muito mais um problema social (ENFB).

Um problema frequente, o álcool é socialmente aceito enquanto ele não causa problema (ENFB).

É um assunto que está bem em voga agora [o das drogas], sendo bem abordado por vários municípios, mais discutido. É um problema de saúde pública (ENFD). 
A droga está permeando toda a sociedade e agora está em pauta pela questão do crack (ENFE).

O uso do álcool e de outras drogas é considerado, atualmente, um sério problema social de difícil solução para os governos. O consumo, o tráfico e a produção ameaçam a comunidade, a família e principalmente a saúde e a vida do usuário. O uso dessas substâncias representa um alto custo social sendo reconhecido como um problema de saúde pública pela Organização Mundial da Saúde (OMS) e pelo $\mathrm{MS}^{(4,7)}$.

No país, os dados sobre uso de álcool são alarmantes. Estudo domiciliar ${ }^{(8)}$ realizado em 2001, que englobou as 107 cidades com mais de 200 mil habitantes (representando 41,3\% da população total do Brasil) revelou que a prevalência da dependência de álcool foi de $11,2 \%$, sendo de $17,1 \%$ para o sexo masculino e $5,7 \%$ para o feminino. Quanto ao uso na vida de álcool e de outras drogas, a prevalência foi de: álcool (68,7\%), maconha $(6,9 \%)$, solventes $(5,8 \%)$ e cocaína $(2,3 \%)$.

Salienta-se a visão dos enfermeiros sobre a temática como sendo um problema social, diferentemente do que se encontra em outros estudos conduzidos no país em que a abordagem do enfermeiro na temática do uso de drogas está focada, especialmente, nos sintomas, ainda vinculada ao modelo biomédico de atenção em saúde ${ }^{(2)}$. Essa visão mais ampla, como um problema de ordem social e familiar, estende as possibilidades de intervenção junto à temática, indo além da prescrição de medicamentos, necessitando, assim, de um suporte multidisciplinar, com perspectivas mais prósperas.

Os enfermeiros referem o uso de álcool e de outras drogas como um reflexo dos problemas familiares e de vulnerabilidade social: acreditam que o início do consumo de álcool e de outras drogas não acontece por acaso, podendo estar relacionado à falta de estrutura familiar e à fuga do indivíduo perante os problemas sociais.

A cultura nestas áreas é a de beber, pela vulnerabilidade social, pois acabam encontrando nas drogas e no álcool uma fuga para os problemas sociais (ENFA).

Nenhum paciente inicia o uso de álcool à toa (ENFC).

Geralmente as drogas lícitas são o início de todas as coisas. O que está havendo é que a droga reflete um problema estrutural, de família, de base familiar, de valores, e acaba sendo a fuga de muita questão social. Na verdade, se tenta "medicar" com a droga, e acaba sendo fuga de muitos, rebeldia de muitos, curiosidade (ENFE).

Nesse contexto, especialistas ${ }^{(7,9)}$ sobre o tema enfatizam que o uso de álcool e de outras drogas geralmente vem junto aos problemas sociais, de saúde, econômicos, jurídicos e legais. Dentre esses, o desemprego, a insegurança em relação ao futuro, a falta de atividades de lazer saudáveis e a educação opressiva são os mais comuns, levando esses indivíduos a buscarem satisfação ou fuga nas drogas.

Em pesquisa realizada com usuários de álcool e de outras drogas, verificou-se que esses indivíduos buscam tais substâncias como instrumento de fuga da realidade, para conseguir esquecer problemas, suportar dificuldades e suprir carências ${ }^{(10)}$. No entanto, precisa-se considerar que muitos usuários não são dependentes, buscando o uso por prazer e/ou diversão, sendo necessária uma abordagem diferenciada. A SF, por ter relação próxima ao indivíduo e a família, precisa estar preparada para detectar e intervir de forma eficaz, seja qual for o caso em que o usuário se encontra.

\section{A família e os agentes comunitários de saúde: um elo}

Nas entrevistas, constatou-se que a principal fonte para detecção de usuários de álcool e de outras drogas é por meio de informações advindas dos Agentes Comunitários de Saúde (ACS) e dos familiares do usuário. Essa detecção, na maioria das vezes, não é realizada pelo enfermeiro. Isso pode estar relacionado à proximidade existente entre os ACS e os familiares junto ao indivíduo, conseguindo, assim, perceber com mais facilidade quando há alguma mudança de comportamento, a partir do conhecimento pelo vínculo prévio com o sujeito/família.

Os enfermeiros entrevistados demonstram o quanto é relevante o trabalho realizado pelos ACS, um elo entre a equipe SF e a comunidade. Reconhecem que os ACS são profissionais imprescindiveis para fornecer informações sobre e para as famílias.

Geralmente os agentes de saúde trazem a informação [...] ou algum familiar (ENFB).

Quem faz esta detecção na verdade é o agente. Raramente tu vais ver um paciente alcoolizado vir consultar. Tem casos que sim, mas não é uma coisa comum (ENFC). 
Os agentes vão às casas, conhecem bem as famílias. Então, geralmente, eles nos trazem o problema, até antes do paciente vir até nós (ENFD).

O agente comunitário é a nossa grande ferramenta: ele é membro da equipe e muitas vezes é através dele (...). Ele é da comunidade e está inserido nela (ENFE).

Os ACS realizam a integração entre a população e a equipe de SF, mantendo-a informada sobre os indivíduos e a comunidade em situação de risco e, por intermédio de visitas domiciliares, acompanham as famílias que estão sob a sua responsabilidade. Tornam-se, dessa forma, um importante elo na criação de vínculo e confiança entre a comunidade e a equipe de saúde. É necessário que mostrem aos usuários que os profissionais de saúde são agentes de saúde e não de repressão ou da justiça.

Porém, segundo alguns enfermeiros, os ACS podem acabar encontrando dificuldades para formar um vínculo de confiança com alguns membros da comunidade. Por fazerem parte da localidade, alguns moradores não se sentem à vontade para relatar, aos agentes, seus problemas ou os de seus familiares, com receio de que sejam expostos de maneira indesejada.

Quem tem que fazer esta ligação é o agente comunitário, e pra eles é difícil porque, segundo eles, os familiares dificilmente expõem que o familiar que mora na casa é usuário de drogas (ENFG).

No entanto, outros enfermeiros citaram a família como agente de detecção do usuário de álcool e de outras drogas, pois, segundo as falas, em muitos casos, quem procura ajuda na USF é o familiar. Quando essa informação chega à unidade de saúde por intermédio dos familiares é porque o uso de drogas já está interferindo não apenas na vida do usuário, mas também na de sua família.

Os familiares ou as pessoas mais próximas do usuário, como vizinhos, amigos, colegas de trabalho, tendem a querer ajudá-lo, buscando um apoio inicial e tentando encaminhá-lo para buscar tratamento.

É mais pelos familiares mesmo, porque é uma característica destas pessoas [usuários de álcool e outras drogas] se manterem mais afastadas (ENFA).
Geralmente é a familia que procura ajuda para ele, que convence ele, que traz ele pra procurar ajuda (ENF D). Pela família que recorre ajuda. Têm várias formas de acesso: a droga (informação) chega aqui, às vezes, como um pedido de socorro da pessoa ou da família (ENFE).

Obtida a informação sobre o usuário de álcool e de outras drogas, a equipe de saúde precisa intervir para tentar resgatar de maneira positiva esse usuário, sempre respeitando a autonomia e a vontade da pessoa envolvida.

A família, independente de sua constituição, classe econômica ou social pode ser surpreendida com o fato do uso de drogas por algum de seus membros. Um fator importante na SF é o vínculo que pode ser construído entre a família e os profissionais da saúde, sendo de fundamental importância as ações realizadas pela equipe de saúde, para que haja impacto sobre a comunidade ${ }^{(11)}$.

Рага isso, é preciso que se rompam os estigmas que acompanham o usuário de drogas e que permeiam a sociedade. Esses estigmas podem partir tanto da família quanto do próprio profissional de saúde, como aponta recente estudo realizado em Salvador, o qual revelou que, no discurso de ACS, a imagem do usuário de drogas é a do negro, com baixa escolaridade, violento, desempregado, envolvido com marginalidade, fadado a morrer cedo e uma ameaça à família ${ }^{(12)}$.

\section{A aproximação, o vínculo, a (des)motivação e as parcerias: os desafios}

Uma das principais dificuldades, na visão dos enfermeiros, é a aproximação ao usuário e à família. Conforme os relatos, alguns indivíduos possuem dificuldades em admitir ou referir que utilizam álcool ou outras drogas, dificultando o manejo, o que diminui as chances de aproximação e de propostas de tratamentos. Outros ainda relatam que os usuários não veem a SF como um mecanismo de tratamento.

É uma população que é difícil de tu te aproximares, então tudo isso dificulta o tratamento. Nossa grande dificuldade é conseguir trazer estas pessoas até a unidade. Muitas vezes a gente acaba indo até a casa, o enfermeiro, o médico, para a gente tentar uma aproximação primeiro (ENFA).

O principal desafio é a pessoa se conscientizar que precisa de tratamento, eles acham que tem o poder de parar 
quando quiser. Dificilmente o usuário considera a unidade básica de saúde como um órgão que ele tem que procurar quando ele ou a família querem ajuda, geralmente eles vão direto a instituições psiquiátricas ou nas casas ou abrigos (ENFD).

O usuário de álcool dificilmente vem aqui por vontade própria. Ele vem, passa por uma consulta, e não volta mais. Quem acaba retornando ao serviço é o familiar (ENFG)

Frequentemente, os usuários de álcool ou de drogas possuem dificuldades em verbalizar sobre si para outra pessoa, pois sentem medo de serem discriminados pelos seus atos (envolve o estigma social da droga), evitando, com isso, a busca por atendimento em saúde. Dessa forma, fazem com que o seu estado de saúde física, psíquica e social se agrave, mantendo-se, muitas vezes, à margem da sociedade.

Nas USFs, as primeiras intervenções a serem realizadas junto aos usuários de drogas e à sua família têm o objetivo de identificar a presença do problema. Após, busca-se motivar o indivíduo para mudar o seu comportamento, sugerindo, assim, estratégias e apoio para que essas atitudes de mudanças sejam tomadas(13).

Segundo relatos, muitos usuários de álcool e de outras drogas mantêm-se afastados da sociedade, e consideram que não precisam de ajuda, por vergonha ou por acharem que possuem total domínio da situação em que se encontram.

O primeiro esforço é trazer esta pessoa até a unidade pra gente conversar e tentar de alguma forma fazer com que ele reconheça que isto é um problema (ENF A).

Quando nós temos essa informação que a pessoa quer o tratamento eu peço para ela procurar o posto. Quando ele não quer o tratamento, a gente o procura, oferece o serviço, tenta convencer e espera ele dar o retorno, não como uma imposição (ENFC).

O mais comum é a família vir e a gente traçar um plano para trazer ele, trazer o usuário; é a gente se deslocar até a casa dele (ENFE).

Há pessoas que se mostram resistentes a receber sugestões de mudanças em suas vidas. Porém, o profissional da saúde precisa lembrar que o usuário não é um adversário a ser derrotado, pois a resolução desse desafio é uma decisão do usuário e não da equipe de saúde. A resistência para mudar é considerada um comportamento normal(13). Salienta-se, ainda, que algumas vezes o usuário procura atendimento em saúde por outras demandas que vão além do uso de drogas, e é nesse momento que o profissional precisa estar atento e aberto para o diálogo.

Evidentemente, quando há desejo próprio do sujeito em mudar o seu comportamento, as intervenções tornam-se mais eficazes. Alguns enfermeiros relatam a importância de o indivíduo querer um tratamento e buscar ajuda com profissionais da saúde. Consideram que a intervenção terá êxito se o usuário quiser a mudança. Caso contrário, as dificuldades impedem que haja um resultado positivo para a sua reabilitação. Sendo assim, o tratamento não deve ser imposto ao sujeito, mas, sim, ser resultado de sua vontade.

O sucesso do tratamento depende da vontade dele. Se eu tentar fazer tudo pra ele, eu não vou conseguir. Eu preciso que ele procure e mostre motivação, (...) mas o primeiro passo depende dele (ENFC).

Não é uma doença qualquer, precisa que a pessoa queira se tratar. Ela é o principal, é onde começa o tratamento (ENF D).

O paciente tem que sentir vontade (...) a gente o acolhe $e$ encaminha o paciente (ENFH).

É difícil estabelecer um vínculo com o usuário, eles acham que não precisam se vincular a nós. É difícil e custoso formar um vínculo (ENFD).

O principal elemento é assegurar um vínculo, só a partir do vínculo que tu podes ter com o paciente é que tu vais planejar alguma atividade, alguma ação em relação à droga. Se tu não tiveres vínculo, nada vai ser feito. $O$ vínculo vai fazer que tu sejas referência da pessoa (ENF H).

Os profissionais da saúde não devem destituir do indivíduo a sua autonomia e o seu desejo, fazendo-os acreditar que os agentes de saúde são detentores do que é melhor para o outro, apesar de, como profissionais, possuírem maior entendimento sobre fatores de proteção à saúde ${ }^{(14)}$.

Segundo os entrevistados, a relação de confiança com o usuário é uma das primeiras etapas para a formação do vínculo, porém é um dos processos mais difíceis de serem cumpridos. Dependendo de como o usuário é acolhido, ele acaba não reconhecendo a unidade de saúde como referência para sua possível reabilitação. 
Desde o primeiro momento, o indivíduo deve sentirse acolhido pelo profissional da saúde que o atendeu, pois a crença na capacidade de mudanças positivas e uma atitude solidária do profissional ajudam a construir e a estabelecer um vínculo entre o usuário e o profissional da saúde. Esse elo construído é essencial para que as ações projetadas e realizadas pela equipe repercutam positivamente na população(11).

Para o sucesso e a continuidade no tratamento, os profissionais da SF buscam firmar parcerias com outros serviços do município, destacando-se os CAPS ad, como pode ser observado nos relatos:

Nós tentamos fazer um serviço articulado com o CAPS ad (ENF B).

No município é mais focalizado no CAPS. Lá eles têm os grupos, e nós encaminhamos para lá (ENF D).

Nós temos vários links, como o CAPS ad. Temos tido sucesso com alguns pacientes de encaminhar e o paciente se vincular a outros serviços também (ENF E).

A gente orienta a família e o paciente a ir ao CAPS ad, que é o local de atendimento para este tipo de paciente e familiar, mas mesmo assim a gente continua acompanhando [o caso] aqui no posto (ENF G).

Ressalta-se a importância de que os atendimentos sejam realizados com a atenção primária, porém existem fatores que impedem essa intervenção: pouca adesão do tratamento, despreparo da equipe para lidar com essa problemática de saúde pública, agravamento dos casos, entre outros fatores.

Para isso, as equipes de atenção primária precisam trabalhar de maneira articulada com outros serviços de saúde para atender a demanda de usuários de álcool e de outras drogas. Entre esses serviços podemos destacar os CAPS ad, que são centros que objetivam reintegrar os usuários à sociedade, reduzindo os danos e os riscos causados pelo uso de drogas ${ }^{(15)}$.

Esses achados diferem daqueles encontrados em estudo realizado com enfermeiros de um município de Amazonas, em que foi observada a falta de referência/contra-referência com a atenção básica, por não haver CAPS na localidade. Os enfermeiros da Amazônia buscavam apoio em Organizações NãoGovernamentais, como a Associação dos Alcoólicos Anônimos(2).
Ademais, destaca-se a importância da articulação entre atenção primária, saúde mental e a atenção aos usuários de álcool e de outras drogas, pois permite um atendimento especializado(7). Entretanto, é importante ressaltar que os CAPS ad são responsáveis pelos casos identificados na comunidade como os mais graves e complexos. Os demais casos, de menor complexidade, devem ser atendidos na atenção básica de saúde, sendo este grupo de pessoas o que representa a maior parcela(16).

Segundo os enfermeiros entrevistados, a falta de capacitação e de motivação da equipe de saúde é um dos desafios encontrados para atender esses usuários: a falta de conhecimento nesse tema faz com que a equipe sinta-se desmotivada para atuar com estes usuários.

Ainda é um tema bem difícil de se tratar em termos de equipe. Na equipe, a maior parte das pessoas tem dificuldades em dizer assim: "vamos fazer um grupo com essas pessoas". É uma coisa difícil (ENF A).

O principal desafio é a motivação da equipe, a equipe tem que conhecer o sistema, o que é dependência química. Se trabalha muito com o "achismo", mas cientificamente a equipe não tem este conhecimento (ENFC).

Um dos principais desafios para tratar o problemas está na necessidade de aperfeiçoar e motivar os profissionais que trabalham prestando assistência aos usuários e seus familiares. Existem vários fatores que interferem nesses aspectos: incapacidade dos profissionais de identificar com antecedência os casos, negação da própria família, estigmas, julgamentos pessimistas em relação ao tratamento, entre outros ${ }^{(17)}$.

Falta uma maior capacitação da equipe, sensibilização dos profissionais sobre o assunto, porque geralmente há um preconceito (ENF B).

Acho até que deveria ter alguma capacitação (...). Eu gostaria que tivesse para saber como chegar e abordar, sem prejudicar ele, pra acolher ele, criar vínculo, para ele confiar em ti. Eu, enfermeira, sinto falta de capacitação neste sentido (ENF F).

A falta de otimismo dos profissionais de saúde diante do tratamento do usuário de drogas pode ser considerada um dos motivos encontrados para que não se efetivem ações relacionadas a esse tema, sendo a 
relação dos profissionais com os usuários marcada, muitas vezes, por antipatia mútua e desconfiança(17).

Uma das formas trabalhadas pelos enfermeiros é a parceria com outras instituições, como as escolas, no sentido de prevenir o problema. Segundo eles, as atividades realizadas em escolas são bem aceitas pelos estudantes, pais e professores, fortalecendo assim o vínculo da USF com as demais instituições da comunidade e formando um elo para a prevenção.

A gente faz trabalho de prevenção nas escolas, nós abordamos bastante este assunto nas escolas. Temos um programa de saúde na escola, em que tentamos fazer isso com as crianças e os adolescentes. Há uma boa aceitação (ENF B).

Nós intervimos, sim, no trabalho de prevenção, junto às escolas; e aqui mesmo na unidade (ENFH).

$\mathrm{Na}$ escola também. [...] antigamente eles [alunos] perguntavam de sexualidade. Hoje eles perguntam sobre drogas. Na última pesquisa que nós fizemos, $90 \%$ dos adolescentes pediram pra abordar sobre o assunto drogas na escola. Achávamos que eles iriam querer sobre sexualidade. Mas desta vez não, pediram sobre drogas (ENF F).

Essas ações extramuro, com escolas e outras instituições, são essenciais para a prevenção ao uso de álcool e de outras drogas. Essa atitude, diferentemente do encontrado em outras realidades ${ }^{(2,5)}$ em que a questão das drogas é tratada pós-evento, demonstra uma visão ampliada do profissional em relação à temática, apontando que a abordagem desses enfermeiros está focada além dos sintomas e do tratamento da doença.

Os enfermeiros também mencionaram que em suas respectivas USF não há programas específicos que atendam os usuários de álcool e de outras drogas. Nos grupos de psicoterapia destinados a atender casos variados, dificilmente surge alguém referindo uso de drogas. Sendo assim, as intervenções realizadas são individualizadas e acompanham cada caso, conforme a necessidade do usuário e segundo os conhecimentos e as atitudes tomadas pela equipe.

Na unidade não há ação específica. A gente tem um grupo de psicoterapia. Nenhum dos participantes da psicoterapia vem por ser usuário (ENFA).
A gente não tem um programa interno dentro da unidade, e esses pacientes acabam entrando em outros programas, não especificamente por ser usuário (ENF B).

A gente não tem grupos para o usuário de drogas. Nós trabalhamos muito mais com a prevenção. Para a construção desses grupos nós precisamos construir um respaldo na sociedade pra que esse grupo acabe tornandose efetivo (ENFC).

Não temos grupo pra atender estes usuários, temos grupo com psicólogo que é aberto pra qualquer pessoa, mas acho que nunca apareceu algum caso (ENFD).

Semelhante ao relato dos enfermeiros, outro estudo(5) também identificou a falta de ações/grupos voltados aos usuários, sendo o atendimento de enfermagem embasado no aconselhamento e no encaminhamento dos usuários aos outros serviços especializados.

Assim, muitas das ações de enfermagem desenvolvidas com os usuários de drogas são heterogêneas e fragmentadas, sendo realizadas de acordo com a ciência de cada profissional. Embora, muitas vezes, os enfermeiros reconheçam as necessidades de intervenção desses usuários, não realizam ações devido à falta de programas de atenção na unidade e à falta de preparo dos profissionais.

Os enfermeiros relataram que, na maioria das vezes, a busca por conhecimento na área é por estímulo próprio. Segundo os entrevistados, não há capacitações voltadas para essa temática, ou pelo menos eles não têm conhecimento de que existam essas capacitações e que sejam oferecidas pelos gestores municipais. Salientaram não receber material das secretarias municipais competentes, porém afirmam que, quando necessário, buscam e recebem auxílio no CAPS para atender casos mais complexos, obter informações e conhecimentos.

Eu busco conhecimento por conta própria, a gente não recebe nenhum tipo de material para falar sobre isso. Eu busco na literatura, na internet: é mais iniciativa individual para poder passar para as agentes (ENFB).

Busco através de bastante literatura, como é um assunto que está bastante na mídia, a gente procura em sites, livros, revistas, e agora estão saindo mais trabalhos também. Mas curso faz tempo que a gente não vê sair (ENF D). 
Interesse próprio, trabalhando, estudando, lendo. Algumas dúvidas tu procuras o CAPS (ENFG).

É fundamental que os profissionais da saúde possuam aptidões em situações que envolvam relacionamentos, tais como: desenvolver trabalho em equipe, saber manejar situações adversas, ter comprometimento com o usuário. Contudo, além disso, precisam ter e demonstrar sabedoria e habilidades, deter conhecimentos teóricos e práticos relacionados à área da saúde em que atuam. Por isso, as equipes de saúde, juntamente com os gestores locais, devem identificar soluções para aperfeiçoar e melhorar o conhecimento dos profissionais envolvidos na atenção primária(18).

Assim, aprimorar a capacitação dos enfermeiros que trabalham na assistência aos usuários de álcool e de outras drogas e a seus familiares, é considerado um desafio. A importância da adequada formação e contínua capacitação da enfermagem é necessária frente ao crescimento do consumo dessas substâncias e por ser um problema social de saúde que traz transtornos para a sociedade $^{(17)}$.

\section{CONSIDERAÇÕES FINAIS}

O estudo aponta alguns resultados já discutidos na literatura, tais como: falta de preparo e capacitação

\section{REFERÊNCIAS}

1. Villar Luis MA, Lunetta ACF. Álcool e outras drogas: leventamento preliminar sobre a pesquisa produzida no Brasil pela enfermagem. Rev Lat Am Enfermagem [Internet]. 2005 [cited 2012 jun 30];13(spe 2): 1219-30. Available from: http://dx.doi.org/10.1590/5010411692005000800018 .

2. Moretti-Pires RO, Ferro SBG, Büchele F, Oliveira HM, Gonçalves MJF. Enfermeiro de Saúde da Família na Amazônia: conceitos e manejo na temática do uso de álcool. Rev Esc Enferm USP [Internet]. 2011 [cited 2012 jun 30];45(4):926-32. Available from: http://dx.doi.org/10.1590/S0080-62342011000400019.

3. Ventura CAA. Drogas lícitas e ilícitas: do direito internacional à legislação brasileira. Rev. Eletr. Enf. [Internet]. 2011 [cited 2012 jun 30]:13(3):554-9. Available from:

http://www.fen.ufg.br/fen revista/v13/n3/pdf/v13n3a22.pdf.

4. Ministério da Saúde. A Política do Ministério da Saúde para atenção integral a usuários de álcool e outras drogas [Internet]. 2nd ed. Brasília: Ministério da Saúde; 2004 [cited 2012 jun 30]. Available from:

http://portal.saude.gov.br/portal/arquivos/pdf/A\%20politica.pdf. 5. Rosenstock KIV, Neves MJ. Papel do enfermeiro da atenção básica de saúde na abordagem ao dependente de drogas em João Pessoa, PB, Brasil. Rev Bras Enferm. 2010 [cited 2012 jun 30]:63(4):581-6. Available from: http://dx.doi.org/10.1590/S003471672010000400013 .

6. Bardin L. Análise de conteúdo. Lisboa: Edições 70; 1995. científica dos profissionais de enfermagem para o atendimento a usuários de álcool e de outras drogas, existência de barreiras para iniciar e manter o tratamento (o que dificulta o vínculo) e falta de grupos especiais, nas USF, para os usuários.

No entanto, sinaliza avanços como a integração da SF com os CAPS ad, a parcerias com escolas para o trabalho de prevenção e a visão do uso de álcool e de outras drogas como um problema social e familiar (não apenas como um problema fisiológico).

Ressalta-se a relevância da atuação dos enfermeiros da SF na detecção e no atendimento de usuários de álcool e de outras drogas, pois esse profissional tem papel importante nas intervenções relacionadas ao tema. Analisando a ênfase desse problema na sociedade atual e os resultados do presente estudo e dos demais envolvendo a temática, faz-se necessário trabalhar com mais veemência a questão do álcool e de outras drogas, tanto nas instituições de ensino quanto na SF, por meio de treinamentos específicos direcionados à área. Na atenção em saúde, deve-se estimular, ainda mais, a articulação entre os diferentes serviços, no intuito de fazer valer a referência-contra-referência. Com essas e outras atitudes, pode-se contribuir para uma intervenção qualificada aos usuários de álcool e de outras drogas.

7. Barros MA, Pillon SC. Programa Saúde da Família: desafios e pontecialidades frente ao uso de drogas. Rev. Eletr. Enf. [Internet]. 2006 [cited 2012 jun 30]:8(1):144-9. Available from: http://www.fen.ufg.br/revista/revista8_1/revisao_02.htm. 8. Carlini EA, Galduróz JCF, Noto AR, Nappo SA. I Levantamento Domiciliar sobre o Uso de Drogas Psicotrópicas no Brasil: Estudo Envolvendo as 107 Maiores Cidades do País: 2001 [Internet]. São Paulo: CEBRID/UNIFESP; 2002 [cited 2012 jun 30]. Available from: http://www.unifesp.br/dpsicobio/cebrid/levantamento brasil/parte 1.pdf.

9. Luis MAV, Pillon SC. O conhecimento dos alunos de enfermagem sobre álcool e drogas. Rev. Eletr. Enf. [Internet]. 2003 [cited 2012 jun 30]:5(1):21-7. Available from:

http://www.fen.ufg.br/fen_revista/revista5 1/drogas.html. 10. Zalaf MRR, Fonseca RMGS. Uso problemático de álcool e outras drogas em moradia estudantil: conhecer para enfrentar. Rev Esc Enferm USP [Internet]. 2009 [cited 2012 jun 30];43(1):132-8.

Available from: http://dx.doi.org/10.1590/S0080$\underline{62342009000100017 .}$

11. Pagani R, Minozzo F, Quaglia G. Abordagem Familiar: cuidado às famílias com pessoas que usam álcool e outras drogas pelas equipes de Saúde da Família. In: Ministério da Saúde. A detecção e atendimento a pessoas usuárias de drogas na rede de Atenção Primária à Saúde. 3rd ed. Brasília: Ministério da Saúde; 2009. p. 3350.

12. Oliveira JFO, McCallum CA, Costa HOG. Representações sociais de Agentes Comunitários de Saúde acerca do consumo de drogas. 
Rev Esc Enferm USP [Internet]. 2010 [cited 2012 jun 30];44(3):611-8. Available from: http://dx.doi.org/10.1590/50080-

62342010000300009 .

13. Micheli D, Formigoni MLOS. Como motivar usuários de risco. In: Ministério da Saúde. Intervenção Breve para casos de uso de risco de substâncias psicoativas. 3rd ed. Brasília: Ministério da Saúde; 2009. p. $12-20$.

14. Vinadé TF. Redução de danos na Atenção Primária à Saúde: construindo a potência do encontro. In: Ministério da Saúde. A detecção e atendimento a pessoas usuárias de drogas na rede de Atenção Primária à Saúde. 3rd ed. Brasília: Ministério da Saúde; 2009. p. 63-75.

15. Pagani R, Simoni C. Ações e programas. In: Ministério da Saúde. A detecção e atendimento a pessoas usuárias de drogas na rede de Atenção Primária à Saúde. 3rd ed. Brasília: Ministério da Saúde; 2009. p. 16-32.

16. Cruz MS, Ferreira SMB. A rede de saúde na assistência a usuários de álcool e outras drogas: papel das UBS, CAPS ad, hospitais gerais e hospitais psiquiátricos. In: Ministério da Saúde. As redes comunitárias e de saúde no atendimento aos usuários e dependentes de substâncias psicoativas. 3rd ed. Brasília: Ministério da Saúde; 2009. p. 30-41.

17. Cruz MS, Silva Filho JF. A formação de profissionais para a assistência de usuários de drogas e a constituição de um novo habitus de cuidado. J. bras. psiquiatr. 2005;54(2):120-6.

18. Gonçalves SSPM, Tavares CMM. Atuação do enfermeiro na atenção ao usuário de álcool e outras drogas nos serviços extrahospitalares. Esc. Anna Nery [Internet]. 2007 [cited 2012 jun 30];11(4):586-92. Available from: http://dx.doi.org/10.1590/S1414$\underline{81452007000400005}$.

Artigo recebido em 01/09/2010.

Aprovado para publicação em 14/03/2012.

Artigo publicado em 30/06/2012. 